\title{
KOLEKSI RHODODENDRON SEBAGAI SALAH SATU TAMAN TEMATIK DI KEBUN RAYA 'EKA KARYA' BALI
}

\author{
D.M.S. Putri ${ }^{1}$
}

\begin{abstract}
ABSTRAK
Rhododendron telah banyak dimanfaatkan sebagai tanaman hias dan merupakan komoditi hortikultura yang penting; baik itu jenis asli ataupun yang telah dihibridisasi. Di Kebun Raya 'Eka Karya' Bali, penggunaan dan pemanfaatan Rhododenron dalam Taman Rhododendron sebagai salah satu taman tematik mengedepankan nilai estetis dan fungsional dengan memperhatikan dua hal mendasar yaitu fungsi taman berdasar konsep tata ruang dan aktivitas yang dapat mendukung tugas dan fungsi Kebun Raya 'Eka Karya' Bali; dan penggunaan elemen seni dan desain.
\end{abstract}

Kata kunci: Kebun Raya Bali, Rhododendron, taman

\begin{abstract}
Rhododendron has been widely used as an ornamental plant and an important horticultural commodity; be it original or hybridized. In Bali Botanic Gardens, the use and utilization of Rhododendron as one of thematic theme park aesthetically and functional with attention to two fundamental things that function of park based on spatial concept and activity that can support task and function of Bali Botanic Gardens; and the use of art and design elements.
\end{abstract}

Keywords: Bali Botanic Gardens, Rhododendron, park.

\section{PENDAHULUAN}

Rhododendron merupakan tanaman berbunga dengan perawakan semak sampai pohon kecil, terestrial atau epifit. Bentuk daun sederhana dan tersusun spiral atau berhadapan berseling. Bunga majemuk (inflorescentia racemosa) atau tunggal dan bunga berbentuk tabung, merupakan bunga banci dengan bakal buah yang menempel pada dasar bunga. Buah berbentuk kapsul yang menjulang ke atas dengan memiliki beberapa biji (Zomlefer, 1994; Argent, et al., 1998; Kurashige, et al., 2001; Craven, et al., 2008).

Rhododendron banyak dijumpai di daerah hutan-hutan pegunungan dengan ketinggian sampai $4.000 \mathrm{~m}$ di atas permukaan laut, namun ada juga yang dapat ditemukan di dataran rendah dan lingkungan mangrove. Tanaman itu dapat tumbuh di tanah berumput dan di batuan. Rhododendron akan tumbuh

\footnotetext{
${ }^{1}$ Staf Peneliti Kebun Raya 'Eka Karya’ Bali-LIPI, dyan.ari79@gmail.com
} 
dengan subur pada tanah yang masam dengan kisaran pH 4,5 - 5,5 (Bowers, 1960; Sekar \& Srivastava, 2010).

Di kawasan Malesia, beberapa Rhododendron merupakan jenis yang potensial terancam kepunahan karena kerusakan habitat. Perbedaan polinator dan waktu berbunga juga menjadi faktor penyumbang yang menyebabkan Rhododendron menjadi terancam (Fay, 1992; Singh and Gurung, 2009). Selain itu ketersediaan bibit/anakan yang sangat sedikit di alam, juga menyebabkan banyak Rhododendron dalam kondisi terancam (Semwal dan Purohit 1980; Singh et all., 2008a; Singh et all., 2008b; Singh 2009).

Beberapa jenisnya telah banyak dimanfaatkan oleh masyarakat sebagai tanaman obat- obatan dan hias. Di kawasan Malesiana, Rhododendron telah banyak dimanfaatkan sebagai tanaman hias dan merupakan komoditi hortikultura yang penting; baik itu jenis asli ataupun yang telah dihibridisasi. Selain itu, sebagian masyarakat di kawasan Asia Tenggara memanfaatkan beberapa jenis Rhododendron sebagai obat-obatan tradisional. Menurut beberapa penelitian yang telah dilakukan di Indonesia, potensi lain dari Rhododendron adalah sebagai antibakterial $(R$. kanori dan $R$. macgregoriae) dan penghasil senyawa flavonoid ( $R$. javanicum dan $R$. macgregoriae). Rhododendron mucronatum varietas juga bermanfaat untuk menghilangkan sakit demam dan perangsang kelenjar (Putri dan Sudiatna, 2009).

Di kawasan Malesia, beberapa Rhododendron merupakan jenis yang potensial terancam kepunahan karena kerusakan habitat. Perbedaan polinator dan waktu berbunga juga menjadi faktor penyumbang yang menyebabkan Rhododendron menjadi terancam (Fay, 1992; Singh and Gurung, 2009). Selain itu ketersediaan bibit/anakan yang sangat sedikit di alam, juga menyebabkan banyak Rhododendron dalam kondisi terancam (Semwal dan Purohit 1980; Singh et all., 2008a; Singh et all., 2008b; Singh 2009).

Penulisan makalah ini diharapkan dapat memberikan informasi pengelolaan koleksi Rhododendron dalam bentuk taman yang secara fugsional bermanfaat dan secara estetis memiliki keindahan.

\section{KONDISI UMUM KEBUN RAYA 'EKA KARYA' BALI DAN PERSYARATAN TUMBUH KOLEKSI RHODODENDRON}

Kebun Raya 'Eka Karya' Bali terletak pada ketinggian $1.250 \mathrm{~m}$ dpl dengan curah hujan berkisar 2.000$3.000 \mathrm{~mm} /$ tahun, kelembaban udara $78-96 \%$, suhu $14-22,5{ }^{\circ} \mathrm{C}$, intensitas cahaya matahari $45-60 \%$, kecepatan angin rata-rata 7,27 km/jam. Jenis tanah regosol kelabu dengan kemasaman 5-6,7 (Hartutiningsih, 2005 dalam Darma dan Hanum, 2009). Dengan kondisi lingkungan seperti tersebut di atas, Rhododendron tidak mengalami gangguan aktivitas fisiologis, misalnya tunas bunga tidak mengalami endodormansi. Selain itu, suhu dan kelembaban juga sangat berpengaruh terhadap pertumbuhan generatif dan vegetatif dengan cara mempengaruhi laju pertumbuhan dan laju perkembangan serta masa hidup tanaman. Laju perkembangan ini mempengaruhi panjang fase vegetatif yang juga menentukan panjang fase reproduktifnya. Dengan terjaganya kelembaban dan suhu udara, maka dapat menjamin sistem perakaran dan proses penyerapan dengan baik, karena media menjadi porous sehingga udara di media cukup bersih dan seimbang dengan keadaan airnya serta $\mathrm{O}_{2}$ tersedia dengan cukup (Putri, 2011).

Pemilihan dan penggunaan media juga sangat penting, menurut Putri dan Sudiatna (2009), Media yang mengandung pasir dan arang sekam yang dapat menciptakan kondisi porous, karena hampir seluruh marga Rhododendron memerlukan aerasi yang baik karena dapat menciptakan kondisi yang porous, menyebabkan pertumbuhan akar tidak terganggu, sehingga aktivitas akar dalam menyerap unsur -

\section{2 | BULETIN UDAYANA MENGABDI}


unsur hara semakin optimal. Secara ekonomis penggunaan arang sekam lebih menguntungkan karena pembuatannya mudah dan relatif murah dibandingkan dengan arang. Hal ini dukung oleh pendapat Kelley dan Drain (1994), bahwa Rhododendron akan tumbuh dengan baik pada sirkulasi air dan udara yang baik, kondisi air yang cukup, tidak kelebihan (excessive water) atau kekurangan (lack of water) air. Hal ini disebabkan akar - akar Rhododendron tumbuh sangat dekat dengan permukaan media, apabila kelebihan akan menyebabkan kebusukan dan apabila kekurangan akan menyebabkan tidak dapat membentuk akar dan menghambat pertumbuhan akar.

\section{TAMAN RHODODENDRON}

Lansekaping merupakan penggabungan elemen-elemen seni dan ilmu pengetahuan untuk menciptakan kehidupan indoor hingga outdoor yang menarik secara estetis dan bermanfaat secara fungsional (Darma dan Hanum, 2009). Dalam pembuatan taman perlu diperhatikan penggunaan elemen taman dan dalam penataannya, elemen-elemen tersebut dipadukan dengan elemen seni dan desain. Elemen taman adalah unsur pembentuk/penyusun taman yang dibedakan menjadi elemen lunak (soft material) yang meliputi tanaman yang berfungsi sebagai koleksi yang ditata berdasarkan habitus dan habitat dan berfungsi sebagai hiasan yang penanamannya berdasarkan nilai estetis; dan elemen keras (hard material) yang berupa lingkungan fisik yang meliputi jalan setapak, gazebo, bak sampah.

Secara fungsional Taman Rhododendron dibuat berdasarkan konsep tata ruang dan aktivitas:

1. Konsep tata ruang

Konsep tata ruang dalam Taman Rhododendron mengacu pada usaha untuk menciptakan miniatur konservasi ex-situ koleksi Rhododendron.

2. Konsep aktivitas

Penataan Taman Rhododendron diharapkan menjadi arena pengembangan aktivitas konservasi, penelitian, pendidikan, rekreasi dan pelayanan yang mengacu pada konsep:

a. Aktivitas konservasi

Berfungsi sebagai tempat mengkonservasi jenis-jenis Rhododendron yang berasal dari Indonesia dan luar negeri dengan dilengkapi informasi botani yang meliputi nama ilmiah, nomer koleksi dan nomor registrasi (akses), serta informasi botani lainnya.

b. Aktivitas penelitian

Keragaman jenis Rhododendron dapat difungsikan sebagai sumber material kegiatan penelitian botani.

c. Aktivitas pendidikan

Berfungsi sebagai media pendidikan yang informasi bagi pengunjung tentang keragaman jenis Rhododendron.

d. Aktivitas rekreasi dan pelayanan

Penataan taman yang mengedepankan nilai estetis akan menarik pengunjung untuk mengetahui keragaman jenis Rhododendron, menjadi tempat untuk menikmati keindahan taman dan sebagai tempat untuk membuat dokumentasi keluarga. Sebagai penunjang pelayanan taman ini dilengkapi dengan jalan setapak, gazebo, bangku taman, bak sampah, dan papan informasi (Gambar 1. dan Gambar 2.). 


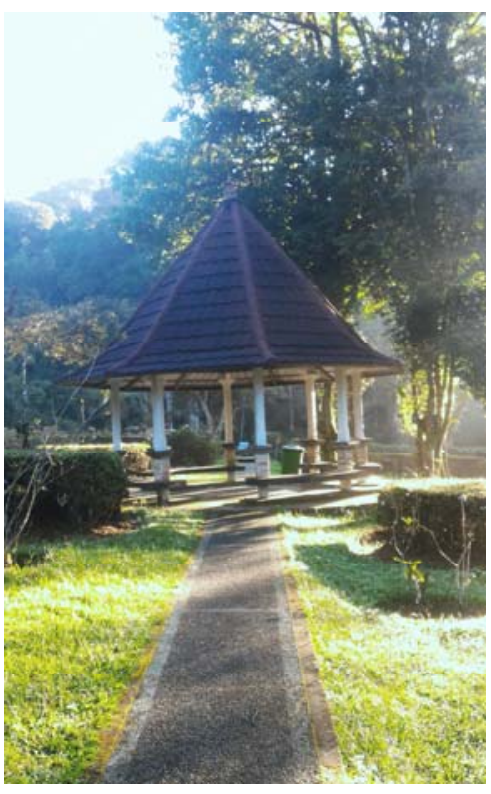

Gambar 1. Ketersediaan gazebo termasuk bangku taman dan tempat sampah sebagai penunjang fungsi aktivitas rekreasi dan pelayanan

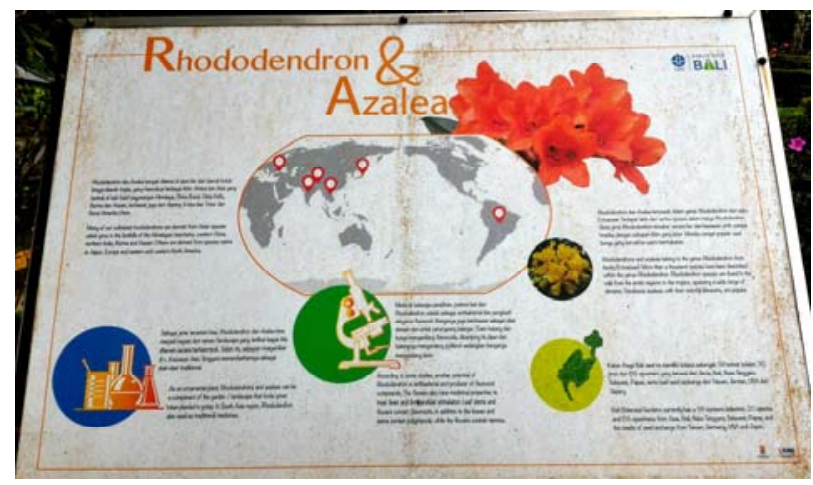

Gambar 2. Ketersediaan papan informasi sebagai penunjang fungsi aktivitas konservasi, pendidikan, serta aktivitas rekreasi dan pelayanan

\section{PENATAAN TAMAN RHODODENDRON}

Taman Rhododendron berlokasi di Petak XIII.B. yang di dalamnya terdapat beberapa Family antara lain Family Cupressaeae, Arecaceae, Melastomataceae, Fabaceae, Pinaceae, Podocarpaceae, Myrtaceae, Lauraceae, Burserace, Rosaceae, Agaveae, Magnoliaceae, Celastraceae, Caprifoliaceae, Moraceae, Urticaceae, Sterculiaceae, Bignniaceae, Casuarinaceae, Cunoniaceae, Araliaceae, Hammelidaceae, Lythraceae, Araliaceae, dan Ericaceae yang merupakan family dari Rhododendron. Jumlah koleksi Rhododendron sebanyak 41 nomor koleksi dan 110 spesimen (data Registrasi Koleksi Mei 2017). 
Perancangan desain dilakukan dengan mempertimbangkan konsep tata ruang aktivitas yang didukung dengan elemen-elemen, baik itu elemen seni (warna, garis, gradasi, tekstur, skala), elemen taman (lunak dan keras). Inventarisasi aspek-aspek biofisik (iklim, tanah, jenis, habitat dan habitus) juga diperlukan agar dapat dipadupadankan dengan konsep tata ruang dan taman yang menunjang fungsi dan tugas Kebun Raya 'Eka Karya’ Bali (Gambar 3. dan Gambar 4.).

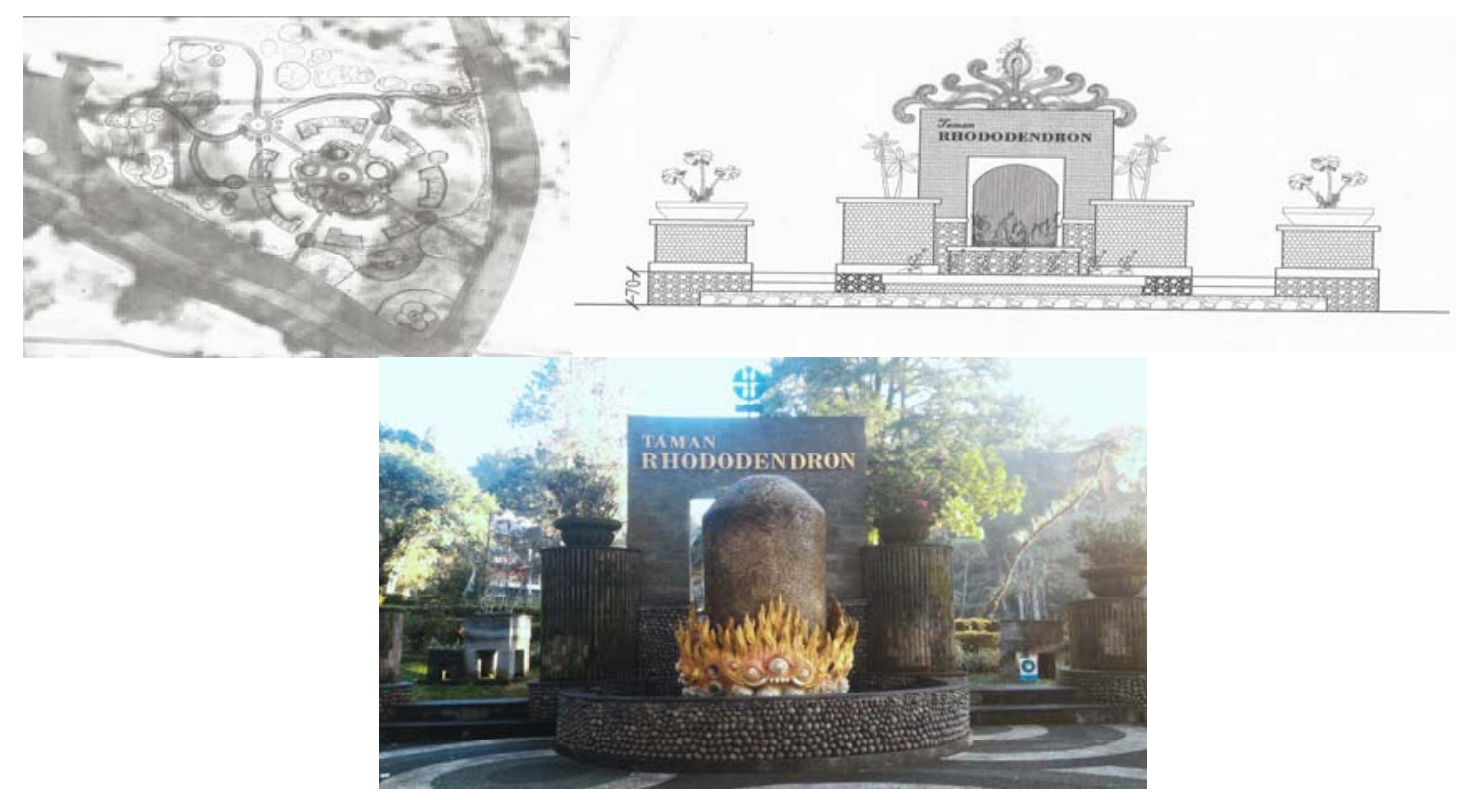

Gambar 3. Konsep desain dan aplikasinya pada Taman Rhododendron.

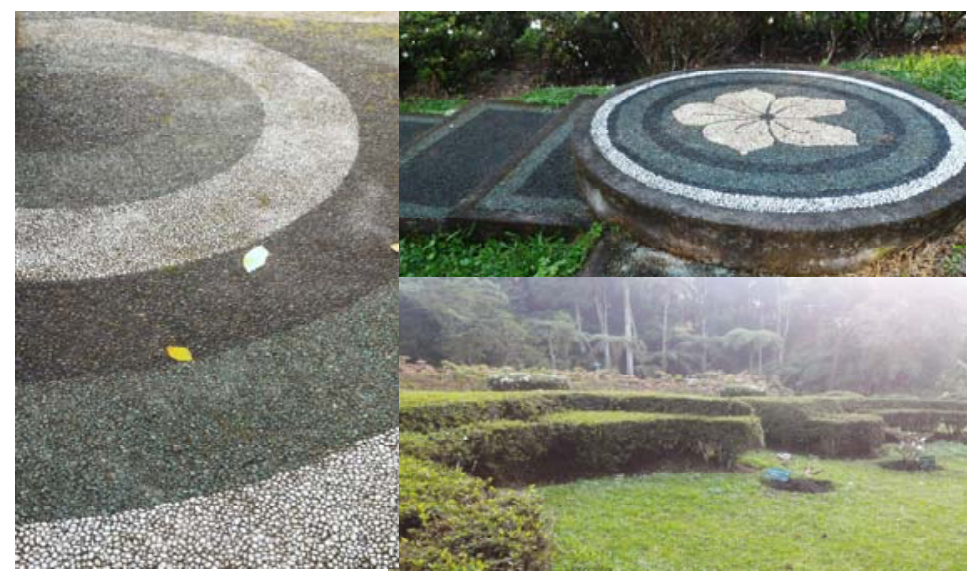

Gambar 4. Penggunaan elemen seni (warna, garis, gradasi, tekstur, skala) dan elemen taman (lunak dan keras) pada jalan setapak dan penataan tanaman Rhododendron. 


\section{KESIMPULAN}

Penataan Taman Rhododendron sebagai salah satu taman tematik di Kebun Raya 'Eka Karya' Bali mengedepankan nilai estetis dan fungsional dengan memperhatikan dua hal mendasar yaitu fungsi taman berdasar konsep tata ruang dan aktivitas yang dapat mendukung tugas dan fungsi Kebun Raya 'Eka Karya' Bali; dan penggunaan elemen seni dan desain.

\section{UCAPAN TERIMA KASIH}

Penulis mengucapkan terima kasih kepada Ir. I Dewa Pt. Darma dan Siti F. Hanum atas diskusi dan proses penyusunan konsep serta staf Sub Unit Pertamanan dan seluruh staf Unit Pemelihara Koleksi selama proses pembuatan Taman Rhododendron Kebun Raya 'Eka Karya' Bali sehingga se;uruh kegiatan dapat berjalan dengan baik dan lancar.

\section{DAFTAR PUSTAKA}

Argent, G., John, B., David, C., Peter, C. and Alan, H. 1998. The Rhododendron Handbook. The Royal Horticultural Society, London. pp.352.

Bowers, C.G. 1960. Rhododendron and Azaleas (Their origins, Cultivation and Development). The Macmillan Company. New York. pp. 525.

Craven, L.A., L.A. Goetsch, B.D. Hall \& G.K. Brown, 2008. Classification of the Vireya group of Rhododendron (Ericaceae). BLUMEA 53: 435-442.

Darma, I.D.P dan S.F. Hanum, 2009. Koleksi Kaktus dan Tumbuhan Sukulen Kebun Raya 'Eka Karya' Bali: Sebuah Tinjauan Analisis Penataan Taman. Warta Kebun Raya. Vol.9 No.1, Mei 2009, Pusat Konservasi Tumbuhan Kebun Raya Bogor, Lembaga Ilmu Pengetahuan Indonesia. Hal: 3-8.

Kurashige, Y., J.-1. Etoh, T. Handa. K.Takayangi. T. Yukawa. 2001. Sectional Relationship in the Genus Rhododendron (Ericaceae): Evidence from matK \& trnK intron Sequences. Plant Syst. Envol. 228:1-14.

Kelley, J.D. and Drain, O. 1994. Top Causes of Death in Rhododendrons. JARS V48: No.2: p85. http://www/Rhododendron.org/v48n2p85.htm Diakses tanggal 22 Nopember 2006.

Putri, D.M.S. 2009. Masa berbunga Beberapa Jenis Rhododendron spp. (Sub.Sect.Vireya) Koleksi Kebun Raya Bali. Prosiding Seminar Peranan Konservasi Flora Indonesia Dalam Mengatasi Dampak Pemanasan Global. Kebun Raya Bali, 14 Juli 2009. Hal 196-205.

Putri, D. M.S. 2011. Fenologi Rhododendron spp. (Subsect. Vireya) Koleksi Kebun Raya 'Eka Karya' Bali. Jurnal Hortikultura Volume 21 No. 3 tahun 2011. Hal: 232-244. ISSN 0853-7097.

Sekar, C.K. \& Srivastava, S.K. 2010. Rhododendrons in Indian Himalayan Region: Diversity and Conservation. American Journal of Plant Sciences, 2010, 1, 131-137.

Semwal, J. K. and Purohit, A. N. Germination of Himalayan Alpine and Temperate Potentilla. Proc. Indian Acad. Sci. 1980;89 61-65.

Singh, K.K., Kumar, S. and Pandey, A. 2008a. Soil Treatments for Improving Seed Germination of Rare and Endangered Sikkim Himalayan Rhododendrons. World Journal of Agricultural Sciences; 4 (2):288-296.

Singh, K.K., Kumar, S., and Shanti, R. 2008b. Raising Planting Materials of Sikkim Himalayan Rhododendron through Vegetative Propagationusing "Air-wet technique". Journal of American Rhododendron Society; 62:136-138.

Zomlefer, W.B. 1994. Guide to Flowering Plant Families. The University of North Carolina, Press. Chapell Hill. London. pp. 438. 